\title{
Discovering Access: Uncovering the Connection between Office Spaces and the User Experience
}

\author{
Tobi Hines and Sara E. Wright \\ Cornell University, USA
}

\section{Introduction}

Since the renovation of our library ten years ago, we have taken a user-centered approach to the improvement of our public spaces. As their needs have changed, we have taken every opportunity to listen to our users in order to create spaces and services that contribute to their success. But can we say the same about our approach to staff office spaces? In our Access Services department, the roles and responsibilities of staff have changed significantly over the past decade, and yet their office workspaces have stayed largely the same. Using many of the same user research methods we have used to study our patrons, we have spent the last year working closely with our staff, using their feedback to design an office environment that will help them be successful in their work. To our surprise, our findings revealed that many of the issues with the staff offices had a direct impact on our circulation desk and the quality of service being offered to our patrons, and what began as a behind-the-scenes effort has become a complete overhaul of our desk and service model. We will share our methods and findings, as well as our plans to renovate the circulation desk and move towards an integrated single service point.

\section{Building the case for new offices}

Before exploring our methods and results in more detail, it is important to understand the role of Access Services and support staff within our library and what prompted the need for new office space. Changes in the services provided by Access Services staff and the level of service expected by patrons have shifted dramatically in the past decade. Gone are the days when support staff positions were primarily focused on staffing a busy circulation desk. With technology-rich and collaborative spaces increasing within libraries and the creation of popular technology lending programs, the support for those spaces and services has been folded into the jobs of our Access Services staff.

In addition to having responsibilities that have expanded beyond the bounds of traditional Access Services work, as staff retire or leave the organization, departments have shrunk and Access Services staff are frequently asked to take on more responsibilities. Overall, the percentage of staff time that is allocated to work the circulation desk each day has dropped dramatically, and the majority of their time is spent focused on other, more specialized tasks: scanning materials for digital course reserves, providing support for specialized equipment, stacks management, $\mathrm{AV} /$ tech assistance for classrooms and conference rooms, interlibrary loan and document delivery, and even programming/coding. This is work that requires dedicated time and focus, and some measure of audio and visual privacy for concentration.

To illustrate just how significantly jobs in Access Services have changed, we have included examples of current staff job descriptions with those of staff from 10 years ago (Appendix A). Staff in our department currently have between 15 and $25 \%$ of their time allocated for circulation desk duties, with the majority of their time spent on other essential tasks. For example, one of our staff members spends about $50 \%$ of his time providing learning and technology support; $25 \%$ of his time providing multimedia instruction for patrons; and only $15 \%$ of his time assisting patrons at the circulation desk. Compare this to a more traditional job description from 10 years ago, when Access Services staff were dedicated to circulation desk functions for almost $50 \%$ of their time, and it is evident how much these positions have changed.

Having convinced library administration that Access Services jobs are not what they used to be, we were given the green light to propose a new office layout and an estimated budget. To inform this proposal and budget, we took an assessment approach similar to what we might do if we were renovating public spaces. 
We did a thorough review of the staff and service space functions in Access Services that needed to be accommodated in any new design:

- Staff office space

- Reshelving area and book trucks

- Hold/reserves/interlibrary loan pick-up shelves

- Equipment and peripherals for loans

- Laptops (short- and long-term loans)

- Plotter printers and supplies

- Staff conference/meeting space

- Student employee space

- Multimedia consultation space

- Payments: fines/fees, printing, posters

- Dedicated staff and student workstations behind the service desk

- Pick-up area for shipping bins

- Staff printers and copier

When we began this assessment process, we believed we had a solid understanding of the issues facing Access Services staff. We knew that we needed additional office spaces, as some staff were being temporarily housed in the interlibrary loan office, away from the rest of the Access Services department. There had also been numerous requests from all staff for more private office spaces that would enable them to do their more focused, quiet work. We were also well aware that supervisors needed more privacy for meetings with staff. Similarly, the conference table where we often had department and small group meetings was frequently coopted by our student staff, as they had nowhere to store their belongings or hang out before/after their shift. There was a very clear need both for staff meeting space as well as storage and break space for student employees.

Beyond the need for better staff offices and meeting spaces, several service areas were in desperate need of improved storage and accessibility. Our specialized equipment for loan, a service that has grown rapidly over the past five years, includes DSLR cameras, audio recorders, podcasting microphones, and more. This equipment was being stored precariously on existing bookshelves, and the charging stations for this technology was haphazardly rigged together with extension cords-a less than ideal set up. Finally, there were highly-circulating items such as course reserves that were located too far away from the circulation desk, and often created the illusion that there was no one available at the desk to assist patrons when, in fact, staff were frequently hunting down items back in the shelving area.

\section{Design methods and results}

Having taken a user-centered approach to the development of many of our public spaces, we decided to take a similar approach to assessing the needs of our staff. We used a mixed methods approach, developing and distributing a staff survey that asked 10 questions about the nature of their work (Appendix B). We followed the survey with in-depth interviews with staff to probe their answers, as well as a card sort activity that allowed staff to rank in order of preference the type of office environment they preferred. Finally, after receiving the initial designs from the interior designer, we had staff provide detailed feedback and suggestions, a step we repeated multiple times throughout the design process.

This process was very eye-opening, and after reviewing the surveys and interviews with staff, certain themes emerged that were consistent across all staff regarding office space.

Office size could be reduced but it was important to have a dedicated space. Many of our support staff had offices that were twice the size of the offices of many of our academic staff at roughly 200-250 square feet. While staff were willing to reduce the size of their space, it was still important to them to have their own dedicated space with walls. An open office environment, a growing trend in offices in many industries, was universally disliked. Though staff understood that, in an open office environment, there would still be an 
opportunity for personalization of spaces, that did not instill enough of a sense of ownership and belonging in the same way that dedicated office spaces would.

More visual and acoustic privacy was needed. The circulation desk is a busy place and there are many distractions and expectations for staff who work the desk. Visual privacy is crucial to helping staff disconnect from the service point without the expectation that they would have to provide service when they were engaged in other tasks. Many of the staff told us that they often put on headphones and listened to music in order to tune out what was happening around them. Open cubicle and office environments bring with them distractions that do not always create the best environment for staff to do their work. In their article, "Challenges of Redesigning Staff Work Space," vanDuinkerken and MacDonald note, "“"Crowding and the sense of loss of privacy contribute to job dissatisfaction because some employees begin to feel frustrated with their inability to focus on their job functions to complete assignments."

All offices contained unused and unnecessary furniture. For better or for worse (mostly for worse), the Access Services area had become a place for all library staff to deposit items that they no longer needed. Because staff in Access Services also handle facilities and maintenance responsibilities, there is an expectation from other staff that they will know how to get rid of something that no one else knows how to get rid of: unused toner cartridges, broken chairs, and outdated laptops. Many of these items will be routed to their proper place for disposal but more often than not, they end up sitting unused in someone's office, taking up valuable space. By identifying items in their offices that were no longer needed, staff started to think about efficiency in their office space that they had not considered previously.

All staff are doing a mix of collaborative and focused, individual work each day. As mentioned previously, the staff in Access Services have seen their job descriptions change drastically in the last 5-10 years. There is a level of technical expertise expected of all staff, whether it is printing a poster, troubleshooting Wi-Fi connectivity issues, or showing patrons how to use the specialized equipment that we circulate. Staff are also frequently asked to join different library project teams or committees and are encouraged to work collaboratively to solve issues, so each staff member's daily schedule includes a mix of meetings, desk shifts, and focused/individual work.

Most staff need multiple work surfaces. As job responsibilities have become more multifaceted, the type of work space needed has changed. Just as our patrons need a variety of work spaces and surfaces, our staff do as well. Having different options in their offices is important, but we also wanted to explore the possibility of creating that variety in some shared "flex spaces" that all staff could use.

Natural light and/or quality of overhead lighting is important. Task lighting and natural light make an enormous difference in our ability to perform the work we need to do. The quality of light affects how much our eyes have to strain and focus, and poor lighting can lead to eye strain and headaches. Our overhead fluorescent office lights often flicker despite regularly changing out the bulbs, and the lighting is zoned, making it difficult to adjust the lighting for one office without affecting other areas nearby.

Much to our surprise-though given the shift in job responsibilities and expectations, perhaps it should not have been-staff were unable to separate their comments about their office environment from comments about the circulation desk. It was clear that, for an office redesign to function the way that staff would like, the desk needed to change as well, which we had not anticipated at the start of this project. We were able to identify consistent themes that emerged regarding the desk layout.

Line of sight to the circulation desk is a double-edged sword. As we continued to talk with staff about their survey responses, it was increasingly clear that the value placed on making sure that all staff had a direct line of sight to the front desk from their offices had created an expectation among staff that they were always on call. As we have given staff more responsibility and asked them to take on work that requires more focus, that expectation to always be available meant that staff felt like they could never do either portion of their job well. Not only were staff feeling like they could not focus on their individual work, but patrons had an unrealistic expectation of staff availability because they could easily see a staff member in his or her office 
who was not getting up to help them at the desk. Our hope was to be able to create an office and desk environment that enabled staff to do the work they needed to do with the freedom from constant interruptions.

Shared workstations for shared tasks. There are many staff that share responsibility for a functional areae.g., course reserves processing-so that we can provide patrons with resources in a timely manner every day of the week. Sharing some of these functions has proven to be problematic when the task is shared between two individual office spaces. Staff would feel uncomfortable intruding on someone else's space to continue the work that needed to be done. Moving the work back and forth between offices was inefficient and did not solve the awkwardness of intruding on each other's space.

Better storage solutions needed for equipment. With a growing equipment lending program, creating adequate storage for that equipment has become crucial. Even circulation desks built as recently as 10 or 15 years ago were not built to accommodate checking equipment out/in, charging devices, and maintaining equipment like projectors, digital cameras, laptops, etc. Designing a desk that would allow for all the processes needed for circulating equipment to be as seamless as possible was a high priority.

Better student employee space with storage. Our previous staff meeting space was a large conference table that was out in the open in a high traffic staff area. As one of the few open staff workspaces, the conference table became the spot for student employees to put their coats, bags, and whatever else they might be carrying with them. Holding a meeting at the conference table became quite labor intensive, having to remove all of the students' items to be able to even sit down. We needed a better storage solution for all of the students' belongings, not only to help ourselves when we needed to meet, but also to create a comfortable space for student employees that showed them how much we value them.

Improved supervisor station. The staff workstation, located between the circulation desk and the staff offices, was cramped and cluttered and did not have enough storage or workspace for items that needed to be processed. Staff would frequently use whatever other surfaces were nearby to store items that were being processed, giving the entire Access Services area a disorganized and disorderly appearance that was in full view of the public.

Easier and better access to high demand items was needed. In the previous desk configuration, students and staff working at the circulation desk had to do quite a bit of traveling to retrieve the high-demand circulating items such as course reserves from the shelving area behind the supervisor workstation. We wanted to move some of our more high-demand items closer to the front desk stations so that these items were more accessible to staff, which would allow us to provide faster service to patrons.

Finally, in our discussions with staff, there were themes that emerged that spanned both the desk and the office spaces.

There is enough space for both the staff and public service functions, but it was not being used efficiently. Most staff felt that the amount of square footage designated for staff offices and for the desk functions was more than adequate but that it was not being used as efficiently as possible. Our challenge was to think through procedures and workflows with a designer to develop a layout that allotted the appropriate amount of spaces to particular functions.

Implicit message with the current state of the desk/office space conveys clutter, chaos, disorder, and "awkward uncertainty" to our patrons. "As the frontline of library public services, circulation is a very visible unit, experiencing all the associated positive and negatives with high visibility. "If the library had a cat, the litter box would be in circulation."”2 This sentiment is certainly one that came out during our interviews with staff about the public perception of Access Services. Perhaps one of the most interesting set of questions we asked staff during the interviews was about the message the current desk configuration and office set-up was conveying to our patrons compared to what message staff wanted it to convey. Staff felt that our current configuration was overwhelmingly sending a message of chaos and clutter to our patrons and 
one that did not provide any clarity on what services are provided at the desk. Across the board, everyone wanted the desk and office space to be welcoming, helpful, efficient, and professional and felt that conveying that first impression would improve the customer transaction from the start.

Modularity and re-configurability of the desk. Our initial thoughts on this new desk reconfiguration was focused on not only making the current functions more efficient, but also allowing for greater flexibility so more functions could be added in the future, such as reference services. In recent years, there has been a "one-stop shopping" trend ${ }^{3}$ for combining service points in academic libraries, and we knew it was a possibility that we could consider this service model in the future. Recognizing that spaces and services have changed on what seems like an annual basis, we wanted our desk to reflect the new normal for libraries: they are always changing. To do this meant that the desk needed to be modular so that it could be easily reconfigured as our needs and patron needs continue to change.

Without a grand budget, we also had to be cognizant of architectural factors that would limit our design decisions-primarily, the current footprint of the desk and offices, our inability to build floor-to-ceiling walls for staff offices, and what might fit nicely with the current furniture aesthetic in the rest of the building.

\section{Combining service points}

As mentioned earlier, the plan to design a modular, moveable service desk was to allow for flexibility in the future to incorporate additional services-namely reference-to be added to this service point. While we thought we would have more time after the installation of the new desk to work with staff to outline a model for creating a single service point, it was ultimately deemed that we should take the opportunity of the desk renovation to combine reference services with circulation and poster printing in time for the fall 2018 semester. This was obviously a much shorter timeline than we had anticipated and presented us with many challenges, not least of which was creating a sense of buy-in with frontline staff.

To complicate matters, the entire first floor was going to be re-carpeted at the same time that we would be installing new staff offices and a new desk and service model. We also experienced unusually high levels of staff turnover in our reference department and we unexpectedly found ourselves short-staffed right before the start of the fall semester. Needless to say, it was a juggling act both from a logistical and personnel perspective. We had a few weeks to modify plans for the desk, talk with reference and Access Services staff about the new service desk/model, and figure out a temporary plan for providing services to patrons during the renovation. Unfortunately, we had little time for developing a shared vision for what a single service point might look like, and what the roles and cross-training expectations would be for staff and student employees.

This is a difficult portion of the desk redesign to discuss because we are only now having the time to think through the staff expectations as thoroughly as we would have liked. One challenge we knew we would have to tackle early on is deciding what level of research support is reasonable to provide at a combined service point, and what needs to be referred to a librarian for a longer consultation. One challenge we did not initially anticipate was the fact that so much support was already happening at the circulation deskeverything from poster printing, holds/reserves/interlibrary loan pick-ups and policy communication, to multimedia consultations, AV help, equipment loans, and room reservation support. This has meant that circulation was a really difficult service to incorporate, and the cross-training of reference staff has proved to be quite challenging.

\section{Present day}

After many construction delays and logistical challenges over the summer, the new staff offices and service desk were installed in the middle of August 2018. Despite our frustrations with the short timeline, we have already seen many positive improvements. With better storage solutions throughout the space, the circulation desk area is tidier and more organized. The most highly-circulating items, such as computer and phone chargers, headphones, and course reserves are located much closer to the front desk workstations. The specialized equipment is now being stored in lockable storage cabinets that are much better-suited for 
equipment storage. The lighter countertop and the lower height of the desk makes it much more approachable for our patrons. In a focus group session conducted to determine what students thought of our new desk, one student noted that the new desk "mimics the feel of the rest of the building now" and is "bright, open and approachable." In an effort to improve our commitment to diversity and inclusion, we adhered to universal design principles and chose a height and depth for the desk that makes it more accessible to patrons with disabilities. We made one section of the desk recessed from the patron side so that it is wheelchair accessible.

The staff offices have also proved to be a big improvement, with higher walls covered in sound absorbing material to provide greater audio privacy. Sliding glass doors allow staff to indicate to each other when they are doing focused work and help prevent frequent interruptions. The student employees have a comfortable new gathering area with soft seating, a group table and chairs, and shelves for storing personal items while they are on shift. The staff conference table, located further away from the student employee area, is now used for its intended purpose of facilitating staff meetings.

There is still much we would like to improve, including more clearly defined roles and responsibilities for reference staff. With little planning time for combining service points, there is a lot that is not working ideally. The location of the reference portion of the service desk is in a prime traffic flow spot on the first floor. While this has led to more interactions with students, the reference area has become the drop-off spot for equipment returns and other materials. Equipment loans have also proved to be challenging, as it takes time to find the patron's reservation in the system, and additional systems outside of the integrated management system used to keep operations functioning have been a training challenge.

\section{Assessment}

The work on the desk is far from over and we are committed to this being a continual process of evaluation and change. To that end, staff have provided a first round of feedback which has been sifted through for common themes/areas of overlap and a prioritized list of areas of effort was established, with work beginning on that in recent weeks. In addition to staff feedback, we are working with two staff members who have training and experience in user experience design who are observing interactions and workflows at the desk and providing a list of areas that they think are problematic. Finally, we plan to do further assessment with our patrons so that we can be sure that, from their perspective, there are not any gaps in service or frustrations with the new design.

\section{Lessons learned}

Throughout this process, it was very challenging to value both sets of users in this scenario-our staff and our patrons. Now that the focus of our work is shifting slightly to assessing whether the new service desk is meeting our patrons' needs, staff need to be reminded that the patron feedback is equally important in evaluating the success of our design. Sometimes the optimal user experience for our patrons does not align with the optimal user experience for staff. Designing a service or space that is mutually beneficial is difficult to navigate and requires an open mind and lot of patience.

Emotional management has been challenging and time-consuming. Soliciting staff input in the manner that we did has opened the feedback floodgates and, while we are thrilled with the level of engagement that it has ignited, the continued suggestions, ideas, and critiques have been a bit overwhelming. Moving forward, we need to find a balance between keeping staff engaged in the process so they feel a sense of ownership and are invested in the improvements, but also keep their expectations reasonable.

Lastly, the changing nature of Access Services work in general (but also in light of the new combined service point) has been a reminder that we should continue to examine our service philosophy to make sure that those customer service expectations are in line with both the work that needs to be done and the number of staff available to complete that work. We want to continue to provide excellent service to our patrons, while recognizing that the retail industry service model is not necessarily the most appropriate for the nature of library work. 


\section{Conclusion}

This project made it clear to us that there was an obvious connection between the office environment and the user experience. When we design state-of-the-art study spaces and classrooms, what we are saying to our patrons is: we see the value in what you are doing, so we are going to create a space that allows you to do it well. This is an important message that should carry over to staff, but it often does not. Staff were feeling stressed about their ability to complete their work in an office environment that was not conducive for the kind of work they were doing, and they were telling us that it was impacting the quality of service at the desk. Not only was their individual work suffering, but the shared responsibilities that took place at the service desk were suffering from an outdated design.

We are intending this to be an ongoing design process, particularly since incorporating reference services into the help desk came very late in the design process. While we were able to make accommodations, the desk had not been designed with this service in mind so our assessment efforts will now be focused more on gathering feedback from students and staff, additional observations, and then modifications to the design or service as needed. User needs-both staff and patrons'-will continue to evolve and we want to make sure that our desk design is responsive to those needs.

Ultimately, it was important to create an office environment where staff felt like they could do their best work. By giving staff space that allows them to remove themselves from the busy desk and do the work they need to do, they will be more focused and attentive when helping our patrons. And by focusing on staff needs, listening to their issues, and incorporating their needs into the design, our hope is that we have communicated to them that they are valued by and provide value to the organization.

-Copyright 2019 Tobi Hines and Sarah E. Wright

\section{Endnotes}

1. vanDuinkerken and MacDonald, "Challenges of Redesigning," 151.

2. Schneiter, "Does Access Services Have a Future?" 213.

3. Crane and Pavy, "One-Stop Shopping," 29-45.

\section{Bibliography}

Crane, Janet and Jeanne A. Pavy. "One-Stop Shopping: Merging Service Points in a University Library." Public Services Quarterly 4, no. 1 (2008): 29-45. https://doi.org/10.1080/15228950802135707.

Schneiter, Thomas E. “Does Access Services Have a Future?” Journal of Access Services 1, no.1 (2002): 211219. https://doi.org/10.1300/J204v01n01_10.

vanDuinkerken, Wyoma and Karen I. MacDonald. "Challenges of Redesigning Staff Work Space.” In Workplace Culture in Academic Libraries: The Early $21^{\text {st }}$ Century Oxford: Chandos Publishing, 2013, 147162.

Wilson, Duane. "Reenvisioning Access Services: A Survey of Access Services Departments in ARL Libraries." Journal of Access Services 10, no. 3 (2013): 153-171. https://doi.org/10.1080/15367967.2013.795430. 


\section{Appendix A}

Figure 1: Access Services Job Description from 2012

RESPONSIBILITIES/ESSENTIAL FUNCTIONS: List the position's assigned responsibilities and estimate percentage of annual time spent on each responsibility. Include only the essential functions that are fundamental and necessary to the position.

\section{Circulation Management}

Approximate $\%$ of time, Annualized

a. Assume responsibility for the day to day management of circulation activity including scheduling, training, and reassignment of staff /student duties, monitoring fine collection and access to the collections; ensure that all software and hardware associated with the Circulation Desk is functioning properly.

b. Set the service standard for the Unit and play a major role in setting, interpreting and consistently enforcing policy and determining operating procedures for the Unit.

c. In tandem with the Night Supervisor, hire, train, and supervise all students who work at the Access Services desk.

d. Coordinate training and follow up training programs for students and staff.

e. Participate in the evaluation of full time staff who work at the Access Services desk.

f. Anticipate trends and suggest new services and technologies to move circulation services forward.

g. Assist with compiling documentation and training staff in the use of the Voyager circulation client.

h. Interpret open ended complex queries from the public; must respond calmly, quickly and appropriately to a wide variety of unpredictable and often simultaneous demands/requests form the public.

i. Maintain familiarity of interlibrary loan, Borrow Direct and reserve services.

j. Maintain a current and thorough knowledge of the Voyager circulation client including the patron file.

k. Perform monthly cleanups of Cornell University Collections reports.

1. Assist the Head of Access Services with Voyager system administration, including the creation of patron records, circulation matrices and calendars.

m. Provide backup to the Head of Access Services for administration of the Citrix Card Access system.

\section{Miscellaneous}

a. Work on special projects for the Head of Access Services

b. Other duties as assigned.

\section{AdDitional COMments: USE EXTRA PAGES IF NECESSARY.}

TOTAL 
Figure 2: Access Services Job Description from 2018

\begin{abstract}
Responsibilities/Essential Functions: List the position's assigned responsibilities and estimate percentage of annual time spent on each responsibility. Include only the essential functions that are fundamental and necessary to the position.
\end{abstract}

Learning \& Technology support

- Assess user and instructor technology needs and recommend appropriate hardware and software in support of teaching and learning at Mann Library

- Provide frontline support for B30A, B30B, \& Stone classroom, working with faculty and instructors to make sure necessary hardware and software are installed, and rooms are in good working order

- Conceptualize, plan, support, and assist with AV upgrades

- Interpret open-ended queries from the public; respond calmly, quickly and appropriately to a wide variety of unpredictable and often simultaneous demands/requests from the public

- Provide AV and video support for events as needed

- Assist in the development and design of educational training materials

- Maintain a high level of technical working knowledge on multimedia equipment for training, maintenance and purchase needs

- Develop and contribute to outreach efforts with special multimedia projects

- Collaborate with public access computing (PAC) team members to provide excellent support and service to the Cornell Community

- Coordinate software requests with the appropriate CUL, CALS, and CHE stakeholders for Mann Library's public access computers.

Multimedia Workshop Assistance and Instruction

- Provide assistance to patrons needing guidance using the library's multimedia technologies for the completion of class-related projects

- Assist Emerging Literacies Librarian with design, implementation, and teaching of workshops and instruction sessions

- Offer one-on-one consultations by appointment with patrons on the use of multimedia equipment and software

User Services Operations

$15 \%$
Approximate \% of time, Annualized

$50 \%$ 


\begin{tabular}{|c|c|}
\hline $\begin{array}{l}\text { Responsibilities/Essential Functions: List the position's assigned responsibilities } \\
\text { and estimate percentage of annual time spent on each responsibility. Include only } \\
\text { the essential functions that are fundamental and necessary to the position. }\end{array}$ & $\begin{array}{l}\text { Approximate \% of time, } \\
\text { Annualized }\end{array}$ \\
\hline 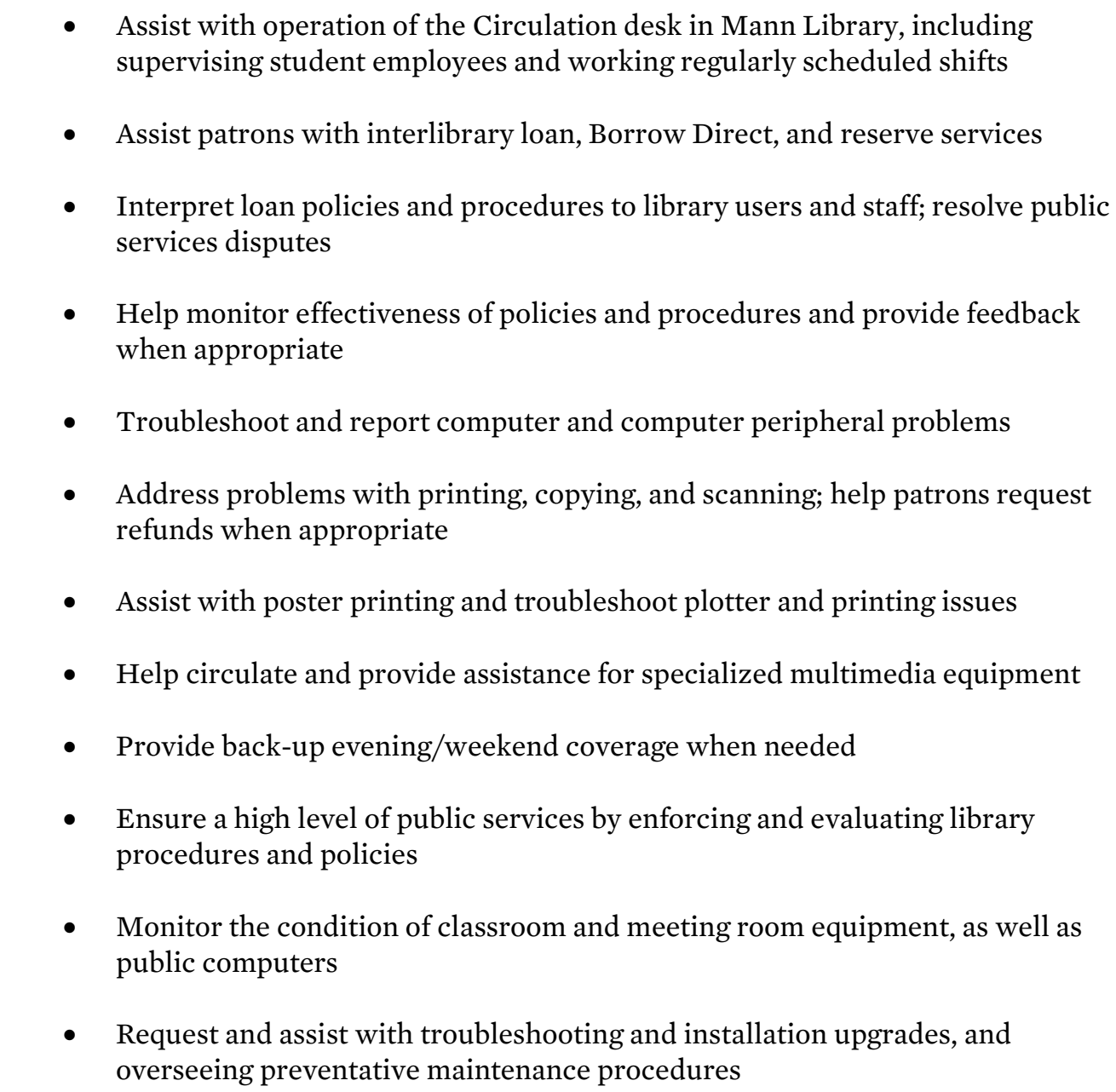 & \\
\hline $\begin{array}{l}\text { Miscellaneous } \\
\text { - Serve on Library and appropriate Cornell campus committees } \\
\text { - Other duties as assigned by the Head of Learning, Spaces, \& Technology }\end{array}$ & $10 \%$ \\
\hline
\end{tabular}




\section{Appendix B}

Access Services staff survey

Access Services Office Redesign

Thank you for taking this space assessment survey! The purpose of this survey is find out more about what type of space and furniture needs you have and how we can best address those needs in the upcoming Access Services office redesign. It should take between 5 and 10 minutes to complete. Please submit your response by the end of the day on Friday, July 28.

Q1 Your Name:

Q2 What type of work are you doing in your office? Please be as detailed as possible.

Q3 Which of your work duties require the most focus/concentration?

Q4 Does any of your work require privacy? If so, please explain. 
Q5 On average, how many hours per day do you spend in your office?

$0-1(1)$

$1-2(2)$

3-5 (3)

$6+(4)$

Q6 On average, how many hours per day do you work on the circulation desk?

$0-1(1)$

$1-2(2)$

3-5 (3)

$6+(4)$

Q7 Is there anything you've wanted to try/work on but space in your office was too limited? If so, please elaborate.

Q8 It would be a game-changer for my work if... 
Q9 What works well about the current layout behind the circulation desk?

Q10 What could be improved about the layout behind the circulation desk?

Q11 Any other comments or requests? 